Final Report:

DOE Grant Number DE-FG02-06ER54876

\title{
U.S. BURNING PLASMA ORGANIZATION ACTIVITIES
}

For the period Jul. 15, 2006 thru Apr. 14, 2008

Raymond J. Fonck

University of Wisconsin-Madison

rjfonck@wisc.edu

(608) 263-779 


\section{Overview}

The national U.S. Burning Plasma Organization (USBPO) was formed to provide an umbrella structure in the U.S. fusion science research community. Its main purpose is the coordination of research activities in the U.S. program relevant to burning plasma science and preparations for participation in the international ITER experiment. This grant provided support for the continuing development and operations of the USBPO in its first years of existence. A central feature of the USBPO is the requirement for broad community participation in and governance of this effort. By hosting the Directorate of the USBPO, the University of Wisconsin had the responsibility of facilitating the development and management of the USBPO with colleagues in the fusion research community, and this grant provided funds to support these activities. We concentrated on five central areas of activity of the USBPO during this grant period. These included: 1) activities of the Director and support staff in continuing management and development of the USBPO activity; 2) activation of the advisory Council; 3) formation and initial research activities of the research community Topical Groups; 4) formation of Task Groups to perform specific burning plasma related research and development activities; 5) integration of the USBPO community with the ITER Project Office as needed to support ITER development in the U.S. The provided budget supported salaries of local staff, travel support for community and professional meeting attendance, and supplies and equipment for initial audio-conferencing and video-conferencing development and conversion of available space to useful remote communications capability.

\section{A) USBPO Infrastructure and Management Development}

We continued developing the infrastructure for the USBPO. This included establishing a management team and protocols, plus development and deployment of tools to facilitate community communication and participation. An overall organization chart of the USBPO is shown in figure 1.

A Directorate was established. It includes the Director, Deputy Director, Administrator and Communication support staff. A position for liaison to the U.S. ITER Project Office to keep communications with that activity as effective as possible was also established. The remainder of the Directorate consists of the leaders of the Topical and Task Groups. The Directorate meets on a frequent basis with the leaders of the USBPO Council to discuss directions and decisions to be taken.

The main activities for the Directorate in the near term concentrated on issues that needed to be addressed to establish the USBPO as a functioning research coordination activity. A partial list of activities pursued included:

- Identification and coordination of community activities in support for ITER Physics needs as identified by the USIPO, the central ITER office, and the US and international communities

- Establishment and facilitation of Topical Group activities to engage the U.S. fusion research community

- Identification and establishment of Task Groups to address specific issues; continuing integration of activities and interests between the USBPO and the ITPA

- Integration of USBPO activities with existing research organizations in the U.S. fusion community, such as the TTF, ECC, SciDac, etc.

- Continuing communication and outreach to the fusion and broader scientific communities. A 
list of sample activities in the community that should be related to USBPO activities is shown in Table 1.

A suite of tools to help USBPO participants communicate and work together from remote locations, thereby lessening the requirements of burdensome travel and additional meetings, was established. A web site and associated forums for two-way interaction with interested community members was deployed, and has been expanded as needed. Subscriber-based group e-mail lists and bulletin boards were developed and supported for the Directorate, Topical Groups, Task Groups, Council, etc. Cooperation with IT personnel at the large fusion facilities (GA, PPPL, LLNL, etc.) defined an expandable path to multi-casting of videoconferences for USBPO meetings. Finally, converting an unused advanced media development room developed a new facility at the UW-Madison for remote communications of routine activities of the USBPO.

\section{B) Council Formation and Activities}

The first USBPO Council was formed, and their activities were central in guiding and defining the USBPO structure. The Council, under the leadership of J. VanDam and A. Hubbard, performed some critical functions in the first years of USBPO formation. In particular, they established a Charter to describe the procedures and protocols to be followed in USBPO activities. They advised the Directorate as needed during the formation of the Topical and Task Groups, and consulted on the choice of leadership in these Groups. The Council also acts as a review group for specific output of the USBPO, such as the white paper that was generated by the Task Group formed to help OFES produce a response to Congressional requirements for a research plan for ITER participation. The first Council membership is listed in Table 2.

\section{C) Topical Group Formation and Task Groups Development}

We established the initial complement of Topical Groups as the basic organizational structure for the research community involvement in burning plasma research activities. The initial set of Topical Groups, as proposed by the community in its discussions at the December 2005 Workshop, is shown in Table 3.

Each of these groups was activated by designation of a leader and one or more co-leaders (as appropriate for each sub-community). These leaders then organized and identified initial activities for that Topical Group. The Directorate chose the group leaders, with review by the Council. The community was solicited for suggestions of leadership candidates.

An especially important activity for these Topical Groups consists of integrating USBPO activities with existing structures in the U.S. fusion research community. Also indicated in Table 3 are community structures whose activities are related to the Topical Group, and with whom the Topical Group are closely aligned. Given the international nature of the burning plasma endeavor, it will be especially important to closely align activities in the U.S. contributions to the ITPA with national USBPO activities. To that end, a memo of understanding was developed between the USBPO and the US leadership of the ITPA activities to formally integrate their activities on the national scale. 
Task Groups under the structure of the USBPO organization were established as needed. These groups comprise relatively small numbers of fusion researchers brought together to address and resolve specific issues relevant to the Burning Plasma research program in the U.S. While the community itself, through the Topical Group activities, may initiate Task Groups, they can also be formed to address pressing issues identified by OFES, the IPO, and the USBPO Directorate or Council.

Several Task Groups were formed immediately to address specific near-term issues. A panel of experts (Table 4) was formed to help OFES form a response to the requirement for a research plan for ITER participation. This requirement was a component of the Energy Policy Act of 2005. The final report from this group was accepted by FESAC and formed the basis for original planning for ITER participation. The final document, Planning for U.S. Fusion Community Participation in the ITER Program, is available on the USBPO and FESAC websites. A CODAC working group was formed under the direction of M. Greenwald of MIT to engage the U.S. community in the international discussion of the control and data acquisition developments for ITER. A short-term Task Group was formed to evaluate and recommend remote collaboration tools for the USBPO and the involved fusion researchers. A major activity that was started but continued beyond the scope of the grant period was the development of Task Groups to address issues of concern in the ITER Design Review activity.

A discussion group within the U.S. fusion community on the relation between burning plasma research and the innovative confinement concepts community was supported. This discussion was meant to focus on the technical relations between these two thrusts in the U.S. fusion program, and may help keep communication between these communities open as the BP enterprise grows.

\section{D) Support Activities}

As mentioned earlier, the USBPO made a variety of remote communications tools available to members to facilitate remote participation in BP research activities. These include: 1) support for teleconferences as needed, as facilitated by the USBPO administration; 2) web-based file sharing; 3 ) Bulletin board support for Task and Topical group work and file exchange; 4) e-mail list servers for easy group communications; 5) supported scalable video-conferencing for small and large group 1discussions; and 6) periodic newsletters to the community. Details are available on the USBPO web site at www.burningplasma.org.

\section{E) APPENDICES}

A few relevant documents are appended here to further describe the USPO structure that was developed during this grant period. They are:

- Charter for the U.S. Burning Plasma Organization

- Bylaws for the US Burning Plasma Organization

- Activity Guidelines of the US Burning Plasma Research Committee

- USBPO and ITPA Coordination in the U.S 


\section{USBPO Comprised of 3 Elements}

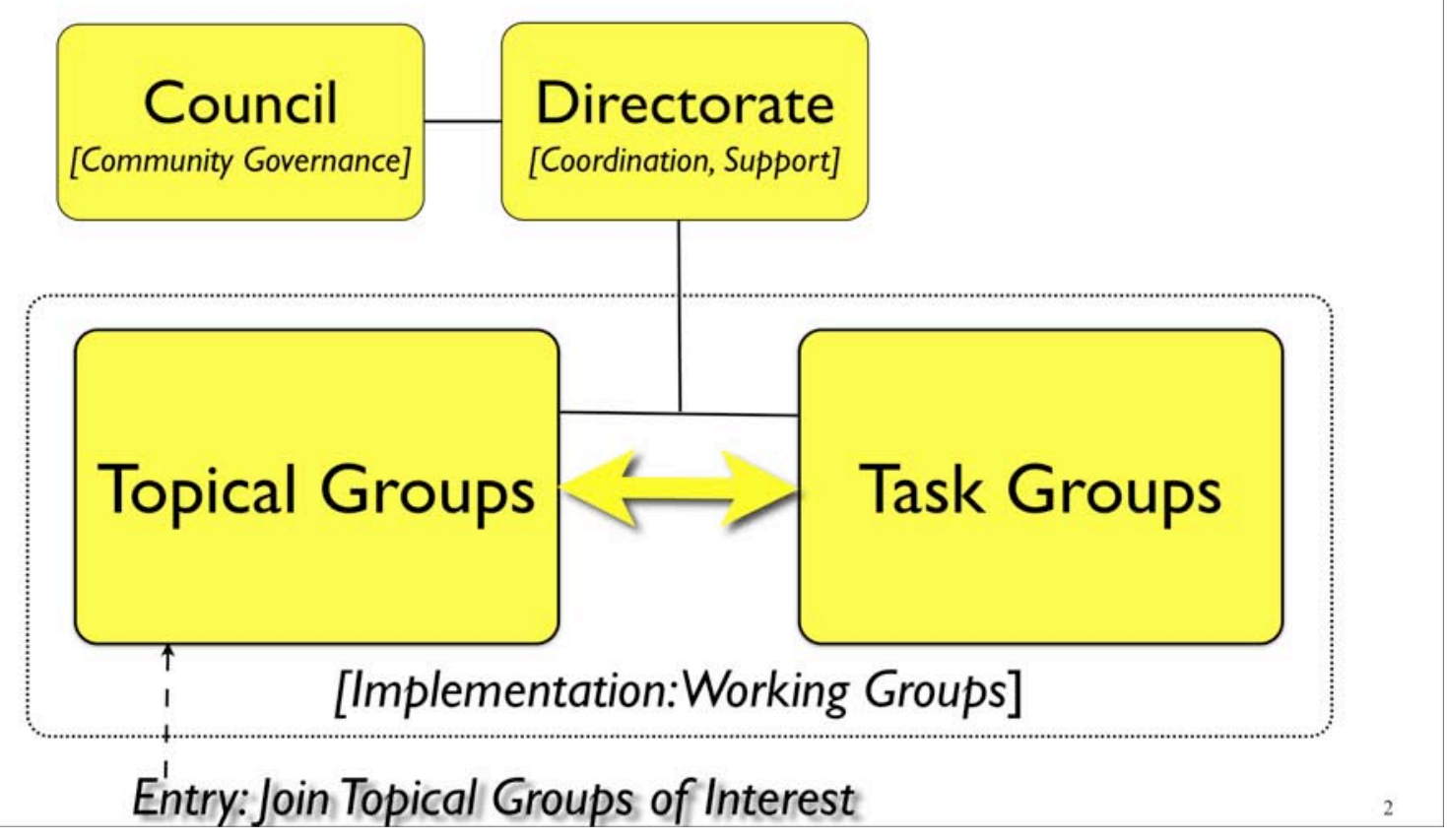

Figure 1. General schematic of USBPO organizational structure. 
Table 1. Some Burning-Plasma-Related Activities and Groups in the U.S. Program

- ITPA

- Diagnostics

- Pedestal \& Edge

- Divertor \& SOL

- MHD

- Confinement database \& modeling

- Transport Physics

- Steady state operation

- Control (working group)

- Tokamak Physics Basis (working group)

- IEA Agreements
- $\quad$ Fusion Facilities Coord Comm

- $\quad$ MHD coord group

- TTF

- $\quad$ Edge Coord Comm

- RF, H\&CD

- FSP

- SciDac

- Theory Coord Comm

- High Temp Plasma Diagnosics

- Individual Grant Activities

Table 2. U.S. Burning Plasma Organization Council - original membership

$\underline{\text { Chair }}=$ James VanDam (U. Texas)

$\underline{\text { Vice-Chair }}=$ Amanda Hubbard (MIT)

Steven Cowley (UCLA)

Richard Hawryluk (PPPL)

Gerald Navratil (Col. U.)

Craig Petty (GA)

Thomas Rognlien (LLNL)

George Tynan (UCSD)
Steven Allen (LLNL)

Earl Marmar (MIT)

Martin Peng (ORNL)

David Petti (INEEL)

John Sarff (U. Wisc.)

Michael Zarnstorff (PPPL)

ex-officio: $\quad$ Stanley Milora (IPO Chief Technologist, ORNL)

Raymond Fonck (USBPO Dir.; IPO Chief Scientist)

OFES Program Managers: $\quad$ Erol Oktay (Science)

Gene Nardella (Technology)

Table 3. First Topical Groups in USBPO 
- MHD, Macroscopic Plasma Physics (ITPA, MHD group)

- Confinement and Transport (ITPA, TTF)

- Plasma-Boundary Interfaces (ITPA, ECC, TTF, VLT/PFC)

- Plasma-wave Interactions (H\&CD, ITPA)

- $\quad$ Energetic Particles (TTF, ITPA)

- Fusion Engineering Science (VLT)

- Modeling and Simulation (FSP, TCC, SciDac, etc.)

- Operations and Control (ITPA)

- Diagnostics (ITPA, HTPD)

- Integrated Scenarios (ITPA)

Table 4. Energy Policy Act Task Group

Chair $=$ R. Fonck $(U W ;$ USBPO $) \quad$ vice-Chair $=$ E. Synakowski $(L L N L)$

Topic 1 - US Research Agenda for ITER
R. Stambaugh (GA)
R. Parker (MIT)
R. Hawryluk (PPPL)
W. Nevins (LLNL)
C. Baker (SNL/UCSD)
H. Berk (UT)

Topic 2 - Methods to evaluate whether ITER is promoting progress towards making fusion a reliable and affordable source of power
D. Meade (PPPL)
F. Najmabadi (UCSD)
M. Greenwald (MIT)
C. Baker (SNL/UCSD)

Topic 3 - Description of how work at ITER will relate to other elements of the US fusion program G. H. Neilson (PPPL)

T. Strait (GA)

M. Mauel (Columbia)

D. Batchelor (ORNL) 


\title{
Charter for the U.S. Burning Plasma Organization
}

\author{
As amended November 13, 2007
}

\section{Introduction}

The US Department of Energy (DOE) Office of Fusion Energy Sciences (OFES), in consultation with the Magnetic Fusion Energy (MFE) research community, created ${ }^{1}$ the U.S. Burning Plasma Organization (USBPO) to achieve the following mission:

Advance the scientific understanding of burning plasmas and ensure the greatest benefit from a burning plasma experiment by coordinating relevant U.S. fusion research with broad community participation.

To accomplish this objective, the USBPO serves the community as the principal organizing body for burning plasma (BP) research activities. It works with other domestic and international fusion $\mathrm{R} \& \mathrm{D}$ bodies to promote, coordinate, prioritize and facilitate the execution of these activities in the U.S., within programmatic and budgetary guidance from OFES. These activities include research in support of the ITER project during construction, and experiments on ITER during operations, research using existing experimental facilities to address BP-relevant issues, development and support of new or upgraded domestic and international experimental facilities, and associated theory and computation that are relevant to BP science and technology. The USBPO also promotes interest and participation in burning plasma research to the broader science and technology communities.

The USBPO is structured to carry out these multiple roles in coordination with the ITER Project and other major MFE program elements. This Charter describes the scope of activities and the overall structure of the USBPO.

\section{Organization and Functions of USBPO Components}

The USBPO is composed of a Membership that is distributed into Topical Groups (TGs), a Council, and a Directorate.

\section{Membership}

Regular Membership in the USBPO is open to researchers and graduate students who are active in burning plasma science and technology research, and whose home institution lies within the U.S.. Associate Membership in the USBPO is open to active fusion researchers whose home institution is outside the U.S.. Membership in the USBPO is established by joining one or more Topical Groups and participating in the research activities of those groups. As such, members are expected to join and participate in one

\footnotetext{
${ }^{1}$ OFES charge letter to form USBPO.
} 
or more Topical Groups. Membership renewal may be requested periodically. Other interested parties may register to receive published information from the USBPO.

\section{Topical Groups and Task Groups}

The Topical Groups represent the resources and expertise of the USBPO. They exist to address the science issues of burning plasmas and provide a venue for community-based burning plasma research. The Topical Groups are the main organizational components of the USBPO, and the center of activity for members of the USBPO. Each group is comprised of fusion community researchers with common interests and expertise in fusion science and technology (e.g., Confinement and Transport, Plasma-Wave Interactions, etc.). These groups provide the knowledge base and research capabilities for the BPO for addressing specific burning-plasma related issues. The Topical Groups stimulate, support, organize, define, and execute burning plasma-related research tasks in the U.S. fusion program. Topical Groups can pursue research tasks within each given group and develop crosscutting research tasks that involve expertise from two or more groups. Topical Groups are the entry point and main focus of activity for U.S. fusion community participants in USBPO research activities.

A Leader and one or two Deputy Leaders lead each Topical Group. They organize, plan, and coordinate the group's efforts to address priority technical issues. These leaders and deputies represent the U.S. Topical Group's activities to the USBPO and to international burning plasma research activities associated with the ITER organization and other international organizations, including the International Tokamak Physics Activity (ITPA).

Task Groups focused on very specific BP issues that cut across the Topical Group boundaries may be formed to carry out work to address those issues.

\section{Directorate}

The USBPO Directorate is composed of the Director, Deputy Director, Research Committee, and support staff. The Director of the USBPO has overall executive responsibility of the USBPO, and is assisted in this role by a Deputy Director. At his/her discretion, the Director can delegate tasks and responsibilities to the Deputy Director. With the review and approval of the Council, the Director proposes, reviews, and updates the Topical Group subject areas.

The leadership of the Topical Groups together with the Director and Deputy Director forms the Research Committee, which coordinates, prioritizes, and manages the Topical Group activities. The Research Committee is led by the Director or his/her designate., The Research Committee will generally focus on nearer-term burning plasma research activities, but will also contribute to long-term strategic planning of burning plasma research in collaboration with the Council. 


\section{Council}

The Council represents the U.S. MFE research community in providing oversight of the USBPO activities, and, working with the Directorate, is the primary USBPO element responsible for long-term strategic planning of burning plasma research. The Council is responsible for setting the policies and procedures of the USBPO, including establishing the by-laws governing USBPO operations. It will receive regular reports on USBPO activities from the Director, and will provide feedback and assessment on those activities to the Director regarding progress, issues, priorities, and opportunities. When required, a simple majority vote of the Council shall serve to designate Council approval of a decision. When Council comment and recommendations are required, the Council Chair and/or Vice-Chair will work to convey the sense of the Council to the Director and the OFES.

\section{Amendments and Bylaws}

Amendments to the USBPO Charter may be proposed by the Director or by the Council Chair, in consultation with OFES, and presented to the Council for approval. A twothirds majority vote of the Council is required for their acceptance. These approved changes shall then be submitted to the OFES for final approval before implementation.

Additions and changes to the bylaws governing the routine operation of the USBPO can be proposed by the Directorate or the Council, and shall be enacted upon a simple majority vote of the Council and approval of the Director and OFES. 


\title{
Bylaws for the US Burning Plasma Organization
}

\author{
As amended November 13, 2007
}

\section{Directorate}

The USBPO Director is appointed by and serves at the pleasure of the Associate Director of the OFES. The Director does not have a fixed term, but will be periodically reviewed by the OFES. The USBPO Council will be called upon to develop a slate of candidates to aid in the selection of the person to serve in this position.

The Deputy Director is chosen by the Director and OFES, with input from the Council, and serves at the pleasure of the USBPO Director. The Deputy Director nominally serves a three-year term and can be reappointed.

The USBPO Director and Deputy Director are expected to be accomplished leaders well versed in the science and technology of burning plasma research.

\section{Research Committee}

Each Topical Group in the USBPO shall have a Leader and no more than two Deputy Leaders. The Leaders and Deputy Leaders of the Topical Groups are members of the Research Committee.

Normally these individuals shall not concurrently be members of the Council. They shall serve two-year terms, renewable once. After serving two full two-year terms as Topical Group Leader or Deputy Leader, a person is ineligible for two years to become the Leader or Deputy Leader of the same Topical Group.

The Director is responsible for appointing the Topical Group Leader and DeputyLeader(s) for each Topical Group, with the advice of the Council and in consultation with the OFES program manager for the USBPO. The candidates for these positions will be developed on the basis of nominations by the membership of the respective Topical Group, discussion with the Research Committee members, and community input as appropriate.

\section{Council}

\section{Council Membership}

The Council has 12 regular members who shall serve staggered terms of three years each. Council members shall not serve consecutive terms.

Elections for Council members from the USBPO community shall be held annually to replace half of the members whose terms are ending. The remainder of the open Council seats shall be filled by appointment, as described below. At least one month prior to the 
election, a small nominating committee with members from both the Council and Research Committee, appointed by the Director and Council Chair, will solicit nominations for the Council from all USBPO members. This committee will put forward a slate of candidates, drawn from the USBPO Regular Membership, to the Council Chair and Vice-Chair, who will then work with the Director's staff to hold an election for the open Council seats. Voting will be open to the USBPO Regular Membership, and open seats filled by those candidates who receive the most votes. In order to maintain institutional balance on the Council, no more than two Council members may be from the same home institution. In the event that the election results would otherwise violate this criterion, the third and subsequent people from a given institution will not be elected.

Following the Council election, the Director, in consultation with the OFES and the continuing or incoming Council Chair and Vice-Chair, shall appoint the balance of the new Council membership, normally two members, in order to ensure broad community representation.

In addition to the members already described, two people will be ex-officio members of the Council with voting privileges: the Chief Technologist and Chief Scientist (if different from the USBPO Director) of the U.S. ITER Project Office. The ITER Science Officer and the ITER Technology Officer at OFES, and the USBPO Director, will be exofficio participants in Council meetings without voting privileges. At the discretion of the Council Chair other individuals may be invited to participate in Council meetings, but will not be voting members.

\section{Council Leadership}

The Council is led by a Council Chair, who is selected from the continuing and incoming Council members by the Director and OFES. A Council Vice-Chair, who is chosen by the Director, OFES, and the Council Chair from among the continuing and incoming Council members, assists the Council Chair. The Chair and Vice-Chair each serve a three-year term, continuing their service on the Council, from the time they assume these positions; thus these Chair and Vice-Chair service periods may supersede the nominal Council member term limit. A serving Vice-Chair can become the new Council Chair.

\section{Council Decision-Making}

A quorum of the Council is defined as at least $60 \%$ of the total Council membership, including voting ex-officio members. A quorum must be available, either in person or remotely, for discussion and debate when a Council vote is required on issues that are discussed in formal Council meetings. Council approval shall consist of a simple majority of those participating in the Council meetings. On specific issues identified in advance by the Council Chair, voting by e-mail may be permitted. In such cases a quorum of the Council must respond with a vote in order to render a decision; a simple majority of this quorum shall suffice to approve a matter being considered by e-mail voting. For changes to the USBPO Charter, a quorum of the Council members must be available to participate in the discussion and to vote. E-mail voting will not be permitted in decisions to change the Charter. 


\section{Activity Guidelines of the US Burning Plasma Research Committee}

The primary role of the Research Committee (RC) is to help define, promote and facilitate burning plasma $(\mathrm{BP})$ research by:

- Coordinating research across multiple programs, facilities and institutions;

- Raising attention and increasing the visibility of BPO activities;

- Facilitating effective communication and coordination between the BPO Topical Groups and national/international organizations (such as the US facilities, ITPA, ITER, ...);

- Promoting communication and collaboration amongst the BPO Topical Groups to enhance the value of the work performed;

- Recommending the formation of special BPO Task Groups that integrate expertise from the Topical Groups;

- Making priority recommendations to the BPO director on tasks that require significant program resources, as required.

\section{Research Task Definition and Formation}

Research tasks can be initiated by the Topical Group membership, the research committee or by the BPO Director. In addition, research tasks can be recommended to the RC by the BPO Council, the US IPO, or by other US fusion organizations. Research tasks are expected to originate primarily from and self-organize within the Topical Groups. The Topical Groups will work to identify, prioritize and execute research in their topical areas through consultation with the RC. The RC can make recommendations for research to be undertaken by the Topical Groups or can recommend the formation of special task groups to undertake specific research activities.

In cases where a proposed task requires a significant redirection of program resources, a formal proposal with task description, goals, near term deliverables, resource requirements etc. needs to be submitted to the RC for further consideration. The BPO directorate may identify tasks that require a formal proposal.

A fundamental requirement of BPO activities is that they be of broad interest and importance to burning plasma (BP) research. Tasks should have clearly defined deliverables and interim goals and they should exploit/develop US strengths through collaborative efforts across US institutions and facilities and international organizations as appropriate. Task descriptions and results will be posted on the BPO web site for dissemination to the wider community.

\section{Approval and Prioritization of BPO Activities}

The larger set of BPO activities undertaken by the Topical groups will be coordinated and facilitated by the Topical Group leaders, who will act as liaison between the task activities and the RC. It is expected that the Topical Group leaders will take the initiative in promoting and 
facilitating these tasks, communicating with task members and in providing regular updates to the $\mathrm{RC}$ on progress in their groups' activities. The BPO director may at his discretion request a written work plan and review by the RC.

Proposed tasks requiring agreement with external organizations (such as ITER physics/ design tasks, etc.) or involving a significant redirection of program resources need to be submitted to the RC for further consideration. The RC will deliberate on formal proposals and approve the task by recommendation to the BPO director. This $\mathrm{RC}$ recommendation will include a work plan with resource requirements and prioritization relative to previous recommendations or ongoing work, when requested. The $\mathrm{RC}$ will prioritize these tasks as deemed necessary by the BPO Director.

\section{Facilitation and Reporting}

Effective task facilitation and empowering of researchers include the following:

- Enhance the visibility of the accomplishments of the BPO tasks by promoting presentations at major scientific and community meetings (such as the APS-DPP, ITPA, BPM, ...), newsletters, web postings, ...;

- Facilitate opportunities for invited presentations at major scientific meetings and encourage the publication of results in scientific journals ...;

- Provide timely input into the facility planning process for run time and resource allocation;

- Coordinate and integrate BPO activities with external organizations, such as ITER, ITPA, etc.

The provision of experimental runtime and other resources on the major US facilities is recognized as one of the key elements in the successful execution of BPO activities. An essential role of the $\mathrm{RC}$ is to provide timely input into the facility planning process regarding recommendations for facility run time and other facility resources together with priority recommendations where necessary. This is similar to the existing voluntary procedure used to promote joint ITPA experiments.

The RC will schedule task or Topical Group leader presentations as part of their regular meeting schedule in order to be apprised of progress and provide feedback on group activities. A brief report on the description of accomplishments including interim deliverables will be presented to the RC for discussion. The Task Groups will edit (if necessary) and post the reports on the BPO web site.

To foster open discussion, BPO members will be encouraged to post their comments and critiques of the task descriptions and reports on the BPO web forum. 


\section{USBPO and ITPA Coordination in the U.S.}

The U.S. Burning Plasma Organization (USBPO) is a national organization with the mission to help define and coordinate Burning Plasma research activities in the U.S. The International Tokamak Physics Activity (ITPA) is an international organization, with a national U.S. component, that aims to identify issues in fusion plasma confinement, and to organize collaborations on large tokamaks in the world and between experiments and theory/modeling to address those issues. Both groups have as a primary goal the support of ITER and its mission to study burning plasmas at the reactor-scale in a large tokamak. They both also support research elements that look outside of and beyond the ITER mission.

The U.S. research community in particular and the international fusion community in general are in the process of defining and developing bridges of communication and cooperation with the ITER central team and researchers in the other ITER parties. Through the office of USBPO Director, who also is the USIPO Chief Scientist, the USIPO acts in that role for issues that impact the design and construction of the device. However, that role does not encompass the full range of forward-looking research activities that need to be pursued before ITER experiments. Additional bridges to the ITER Organization are beneficial. One proposal is that the ITPA evolve to provide a link between the national research communities and the ITER project. The ITPA can serve as a vehicle over the next ten years to nucleate international teams of researchers that can conduct burning plasma research on existing facilities and plan for research on ITER. As the relevant physics organization in the U.S., the USBPO will guide burning-plasmarelevant physics research pursued by the U.S. community and eventually act as the U.S. ITER physics team. In that role, the USBPO can support the involvement of U.S. researchers in ITPA activities and their interactions with the ITER team. The USBPO is also responsible for outreach to the fusion community, the broader research communities, and the general public for burning plasma research.

The ITER program is undergoing a transition itself and hence many issues have yet to be decided. Discussions are ongoing to redefine the relationship of ITER and the ITPA. It is timely to consider and define the relationship between the USBPO and the ITPA activities on the national scale. Some questions to answer include:

- How can the activities of the USBPO and U.S. members of the ITPA be defined and integrated to avoid overlap and/or duplication in the community?

- How can people know what is going on and how to get involved?

- How can these activities be defined to keep these organizations separate but interrelated, with the understanding that they have different forms of governance and methods of community participation?

- What is the role of the USBPO and ITPA U.S. participants in completing U.S. physics tasks in support of burning plasmas and in support of ITER?

To address these questions and clarify the scope of operations on the national level, this discussion presents the plan for integrating the research activities in the U.S. of the 
USBPO and U.S. participants in ITPA.

\section{Responsibilities and Benefits of Coordination:}

To support USBPO activities, the U.S. participants in the ITPA will:

- Act as a critical conduit to the international tokamak and stellarator communities

- Provide a potential main conduit to ITER IO, as this role of the ITPA develops

- Brings results of ITPA activities back to BPO Topical Groups, thereby connecting USBPO groups to the international community

- Provide a conduit for USBPO members to cooperate on international experiments

- Execute BP-research of interest to the U.S. community in the international realm

To support the activities of the ITPA in the U.S., the USBPO will:

- Provide the national organizational structure for ITPA activities in the U.S.

- Help provide U.S. resources and participants to support ITPA participation

- Provide inputs from USBPO researchers to ITPA activities

- Act as the community entrée to ITPA participation

- Publicize ITPA activities and results to the wider U.S. community

- Routinely communicate ITPA activities via BPO e-News, web site, etc.

- Support/facilitate execution of priority ITPA research in the U.S., as needed

- Engage broader U.S. community in suggesting new avenues for ITPA activities

- Help nucleate domestic BP research teams to contribute to international activities

\section{Action: Integration of ITPA and USBPO activities at the national scale}

The USBPO will be responsible for managing U.S. participation in ITPA activities. It will support, coordinate, and facilitate participation in ITPA activities from the U.S. USBPO Topical Group leaders will work with their related ITPA Topical Group national coordinators to assure maximum benefit of U.S. participation in ITPA activities. Representative responsibilities include: publicizing and aiding preparations for upcoming ITPA meetings; working with the national ITPA coordinators to identify participants as needed; disseminating results from ITPA meetings to the broader fusion community; and acting as the point of contact between the ITPA and the U.S. fusion research community.

To clarify the responsibility for participation in each ITPA activity, the USBPO and national ITPA coordinators will assign responsibility for managing participation in an ITPA Topical Group to one or more related USBPO Topical Groups. The ITPA activities will be then be embedded in the designated USBPO Topical Groups. The ITPA participants will simultaneously be members of their respective Topical Groups of interest. In this role, ITPA activities and interests will be integrated into the BPO Topical Groups. Greatest efficiency of interaction of working level scientists is promoted by having good alignment of the BPO organizational structure, the ITPA organizational structure, and the ITER Science and Technology Directorate structure. The extent to which such alignment can be achieved at any given time will evolve and hence will need to be periodically reviewed. An initial mapping between the ITPA and USBPO Topical Groups is shown in the figure. 


\section{USBPO - ITPA Topical Group Responsibilities: \\ USBPO \\ ITPA}
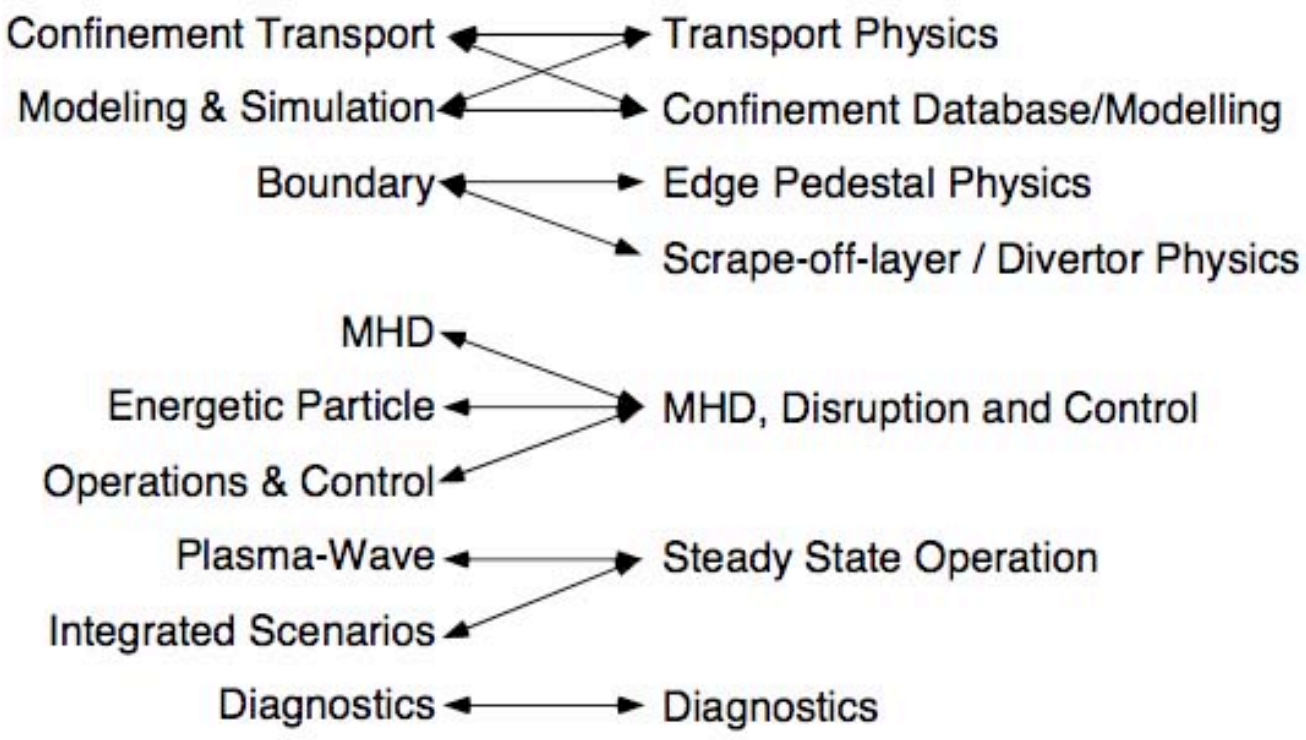

Engineering Science

Note: There is currently no corresponding ITPA group for Engineering Science. This USBPO Topical Group serves as a crosscutting technical resource for all of the other USBPO groups as required. 